\title{
AVALIAÇÃO DA GESTÃO DA FLORESTA NACIONAL DO TAPAJÓS, BELTERRA-PA, NA PERCEPÇÃO DOS MORADORES DA COMUNIDADE MAGUARI
}

SANTOS, Grace Rente dos. Mestranda em Ciências Florestais e Ambientais. Universidade Federal do Amazonas. Av. General Rodrigo Octávio Jordão, 3000. Campus Universitário - Setor Sul (Mini-Campus). Bloco F. 69077-000. Manaus/AM. E-mail: gracerente@yahoo.com.br.

BARBOSA FILHO, José. Universidade Federal do Amazonas. E-mail: jbarbosa@ufam.edu.br. COELHO, Lucyanna Moura. Doutoranda em Biotecnologia. Universidade Federal do Amazonas.

E-mail: lucyannacoelho@ outlook.com

\section{RESUMO}

A presente pesquisa propôs avaliar a gestão adotada na Floresta Nacional - Flona Tapajós, na Comunidade Maguari, no município de Belterra-PA, de acordo com a percepção dos moradores. Para isso, foi realizada uma pesquisa explorativa constituída, inicialmente, por uma revisão bibliográfica sobre o tema, seguida de uma pesquisa de campo tendo pesquisa de campo tendo como instrumento de coleta de dados a aplicação de 146 questionários/entrevistas aos moradores da Comunidade Maguari. Dentre os moradores entrevistados da Comunidade Maguari, $85 \%$ afirmam, do ponto de vista pessoal, que a gestão da Flona Tapajós é eficiente e $76 \%$ acreditam que a população local está de acordo com a gestão. Quanto ao grau de aprovação da eficácia da gestão na Flona do Tapajós, 51\% disseram ser bom. Grande parte dos entrevistados (92\%) reconhece que há limites a respeito do uso dos recursos naturais dentro da Comunidade Maguari. Estes afirmaram que cursos, treinamentos e reuniões são atividades que faltam para a Comunidade Maguari. Os moradores sentem a necessidade de cursos de qualificação profissional, de estarem mais informados com o que acontece em relação à Flona e, principalmente, o que envolve a Comunidade Maguari. As intervenções realizadas na Flona do Tapajós ocorrem por meio de inúmeros projetos e programas direcionados à mudança de comportamento dos moradores de Maguari quanto à preservação e conservação do meio ambiente, mas o modelo de gestão adotada pela Floresta Nacional do Tapajós ainda deixa a desejar, segundo a percepção dos moradores da Comunidade, mesmo com um plano de manejo existente.

Palavras-chave: Unidade de Conservação; Flona-Tapajós; Gestão ambiental.

An evaluation of the management of Floresta Nacional do Tapajós, Belterra-Pa, in the Perception of the Residents of Maguari Community

\section{Abstract}

The present research proposed to assess the management adopted on TNF in the city of Belterra-PA according to the perception of the residents. With this aim, an exploratory research was developed, consisted, initially, of a literature review on the topic followed by a field research, using as data collection instrument the application of 146 questionnaires/interviews to Maguari community residents. One of the residents interviewed, $85 \%$ Maguari community claim, from a personal standpoint, that the management of the Flona Tapajos is efficient and $76 \%$ believe that the local population is under this management. The degree of adoption of effective management in the TNF, $51 \%$ said it was good. The majority of respondents $(92 \%)$ recognizes that 
there are limits regarding use of natural resources within the Maguari Community. The residents feel the need of professional qualification courses, they are more informed about what happens in relation to the Tnf and, mainly, which involves the Maguari Community. The interventions performed on the TNF occur through numerous projects and programs directed to the change in the behavior of Maguari community residents regarding the preservation and conservation of the environment, but the management model adopted by the Tapajós national forest still leaves something to be desired, according to the perception of the residents of the community, even in the presence of a management plan.

Keywords: Conservation unit; FLONA- Tapajos; Environmental management.

\section{INTRODUÇÃO}

O crescimento das atividades econômicas e a própria expansão urbana, impreterivelmente, acarretam problemas ambientais, visto que trazem consigo, por exemplo, a extração de madeira para indústrias, extrativismo mineral, abertura de loteamentos residenciais em áreas de preservação ambiental, dentre outros setores e atividades que resultam em efeitos danosos ao ambiente físico e tambémà população local (PEREIRA, 2004).

Os primeiros grandes impactos surgiram na década de 50, e a noção do surgimento da existência de problemas ambientais reais fez com que a população mundial começasse a se organizar e lutar pelo meio ambiente. Ocupação e degradação de áreas de grande fragilidade ambiental, assoreamento de leitos de rios e igarapés, poluição do solo através de resíduos sólidos, dejetos despejados diretamente na água, queimadas desordenadas, desmatamentos violentos são apenas alguns dos problemas ambientais que o planeta enfrenta.

Essa problemática ambiental é a grande preocupação no momento e cada passo dado foi importante, delimitando-a em áreas protegidas, que nasceram no Brasil com o Sistema Nacional de Unidades de Conservação da Natureza - SNUC, de
18 de julho de 2000, com a Lei 9.985, pois até então não havia leis específicas, como marco regulatório pertinente ao tema antes desta, e sim leis esparsas, no arbítrio de órgãos responsáveis por sua criação, tendo o objetivo de conservar, e nasce o SNUC como instrumento a ser utilizado para auxiliar as Políticas Nacionais do Meio Ambiente, principalmente em Unidades de Conservação (MMA, 2011).

Atualmente, as unidades de conservação representam a principal proposta para diminuir os efeitos de degradação de ecossistemas no Brasil, e existem para manter a diversidade biológica e os recursos genéticos no país, contribuindo na proteção das espécies ameaçadas de extinção, preservação e restauração da diversidade de ecossistemas naturais e promoção da sustentabilidade do uso dos recursos naturais.

Por meio das Políticas Nacionais de Meio Ambiente e seus Instrumentos, Lei 6.938/81, a FLONA Tapajós foi criada com objetivo principal da preservação, melhoria e recuperação da qualidade ambiental que propicie a vida, assegurada ao país, condições ao desenvolvimento socioeconômico, e aos interesses da segurança nacional, sendo esta um gerador de benefícios sociais que foi disposto na Lei 9.985/2000.

Com isso, as pesquisas em Unidades de Conservação são extremamente relevantes, visto que esses espaços apresentam características naturais com função de assegurar a representatividade de amostras significativas das diferentes populações, habitats e ecossistemas do território nacional, com função de preservar o patrimônio biológico existente.

No entanto, para que atinjam seus objetivos de conservação e o aporte de benefícios esperados, é necessário que a seleção e o delineamento dessas áreas sejam pautados em um processo de planejamento abordando fatores ambientais, sociais e econômicos que de fato estejam em consonância com a realidade local. Dessa forma, espera-se que as pressões negativas sobre a área possam ser amenizadas e as pressões positivas, potencializadas.

Portanto, um conhecimento maior da FLONA Tapajós e o seu consequente monitoramento são 
urgentes para que qualquer estratégia de conservação seja bem-sucedida. Nesse sentido, os resultados desta pesquisa, na Comunidade Maguari, viabilizarão informações estratégicas para a tomada de decisão na gestão adotada na unidade de conservação e, proporcionando essa resposta, oferecerá maiores garantias para a conservação e possibilidades para o desenvolvimento de umenfoque mais específico voltado para o entendimento da biodiversidade em todos os seus níveis locais.

\section{Material e métodos}

A presente pesquisa propôs avaliar a gestão adotada na FLONA Tapajós, na Comunidade Maguari, no município de Belterra-PA, de acordo com a percepção dos moradores. O presente estudo teve com base a pesquisa exploratória, da qual as informações obtidas subsidiaram o contexto teórico e evidenciaram a situação real. O método de avaliação da participação dos entrevistados foi por meio de aplicação de entrevistas semiestruturadas, em que se pretendeu saber até que ponto ocorre o envolvimento da população com os possíveis impactos decorrentes das atividades desenvolvidas na gestão da Floresta Nacional do Tapajós.

A Floresta Nacional do Tapajós localiza-se no Oeste do Estado do Pará, abrangendo os municípios de Aveiro, Belterra, Placas e Rurópolis, com uma área de aproximadamente 545 ha. Suas coordenadas geográficas correspondem a $2^{\circ} 45^{\prime}$ a $4^{\circ} 10^{\prime} \mathrm{S}$ e $54^{\circ} 45^{\prime}$ a $55^{\circ} 30^{\prime} \mathrm{W}$. Limita-se ao norte com o paralelo que cruza o km 50 da Rodovia Santarém-Cuiabá (BR 163); ao sulcom a Rodovia Transamazônica e os rios Cupari e Cuparaitinga ou Santa Cruz; a leste com a Rodovia Santarém-Cuiabá (BR 163); e a oeste com o rio Tapajós (Figura 1).

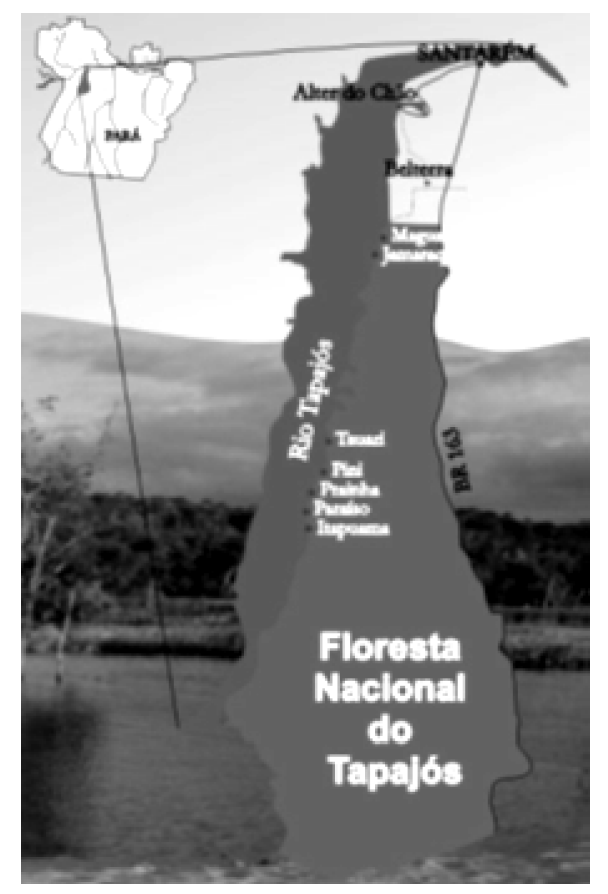

Figura 1 - Localização geográfica da Floresta Nacional do Tapajós.

Fonte: Ibama/ProManejo (2005). 
Neste estudo foram utilizados os métodos indutivo e hipotético dedutivo, com aplicação de questionários com perguntas estruturadas (tipos sistemáticas) e perguntas não estruturadas (são chamadas de livres, assistemáticas ou antropológicas) aos moradores da Comunidade Maguari. Esses resultados foram transformados em porcentageme, posteriormente, com o auxílio do programa Microsoft Office Excel 2010, expostos de forma descritiva.

A aplicação dos questionários foi direcionada aos moradores da Comunidade e deu-se de forma aleatória, desde que estivessem em casa dois indivíduos por família, independente de gênero, podendo ser masculino ou feminino, desde que maior de 18 anos.

Após a obtenção das informações e análise preliminar, constatadas no local, posteriormente os dados de coleta foram organizados, analisados e interpretados à luz da teoria da percepção ambiental.

O tamanho da amostra foi determinado com base na distribuição de probabilidade estatística de "tStudent". Foi utilizado o modelo estratégico para teste de hipóteses de média populacional, com variância populacional desconhecida, considerando um nível de significância de 5\% $(\alpha=0,05)$ e as seguintes hipóteses.

Para estimar o valor da distribuição "t-student", foram utilizadas as equações:

$$
\begin{aligned}
& E q(0.1) \quad n o=\frac{t^{2 *} p^{*} q}{d^{2}} \\
& E q(0.2) \quad n=\frac{n o}{\left[\begin{array}{c}
1+(n o) \\
N
\end{array}\right]}
\end{aligned}
$$

Onde:

no = estimativa do tamanho da amostra;

$\mathrm{t}=$ valor da distribuição $\mathrm{t}$-student associado ao nível de confiança $(\alpha=5 \%$,);

$\mathrm{p}=$ probabilidade de $\mathrm{o}$ entrevistado aceitar responder o questionário $(q=0,5)$;

$\mathrm{q}=$ probabilidade do entrevistado não aceitar responder o questionário $(q=0,5)$;

$\mathrm{d}=$ erro permitido $(\mathrm{d}=0,05)$; $\mathrm{n}=$ tamanho da amostra= 146 indivíduos

$\mathrm{N}=$ tamanho da população $=318$ indivíduos

Para atingir o objetivo principal do trabalho, utilizou-se o teste de hipóteses para média com variância populacional desconhecida, conforme Equação 0.3, descrita abaixo.

$$
\operatorname{Eq}(0.3) \quad t=\frac{\bar{x}-\mu_{o}}{\frac{s}{\sqrt{n}}}
$$

Onde:

$\mathbf{x}=$ Média da amostra;

$\mu_{\mathbf{o}}=$ Valor fixo usado para comparação com a média da amostra;

$\mathbf{S}=$ Desvio padrão amostral;

$\mathbf{n}=$ Tamanho da amostra.

\section{Amostragem}

\section{a) Critério de Inclusão}

Foram incluídas 146 pessoas (número definido de acordo com a equação "t-student"), escolhidas de forma aleatória na comunidade Maguari. Todos os participantes da amostra foram previamente informados sobre o conteúdo da pesquisa, seus benefícios e potenciais risco; em seguida, foram submetidos a um Termo de Consentimento e Livre Esclarecido - TCLE anexados a esta proposta. Apenas as pessoas que concordaram e assinaram o Termo de Consentimento compuseram a amostra da pesquisa. A participação das pessoas foi de forma altruísta, não comercial e voluntária, sob nenhuma hipótese acarretando perdas ou prejuízos àqueles que se negaram a concordar com o TCLE.

\section{b) Critério de Exclusão}

Foram excluídas todas as pessoas que não residiam na comunidade Maguari, de etnia indígena, menores de 18 anos de idade sem emancipação legal, os participantes da amostra que, eventualmente, solicitaram ser removidos da amostra, a qualquer momento, bem como todos aqueles que não 
concordaram em assinar o TCLE ou àqueles que não cooperaram para o seguimento ético do presente estudo.

c) Riscos

Segundo a Resolução 196/1996 do Conselho Nacional de Saúde, não há pesquisa com seres humanos sem risco. Esta pesquisa não expôs a população a riscos previsíveis, a comunidade esteve exposta apenas aos riscos já presentes no seu cotidiano: doenças endêmicas da região ou riscos adversos da dinâmica natural fluvial (cheia/vazante). Portanto, o presente estudo não acrescentou riscos além daqueles a que a população da amostra já estava naturalmente exposta.

d) Benefícios

Conhecimento procedente da pesquisa que contribuirá para o desenvolvimento de alternativas efetivas para intervenção no futuro. Pesquisas com populações tradicionais são de grande relevância, pois estas populações assumiram um papel de suma importância dentro do conceito de desenvolvimento sustentável.

\section{Considerações Éticas}

Este Projeto de Pesquisa, com o título "Avaliação da Gestão Da Floresta Nacional Do Tapajós, BelterraPA na Percepção dos Moradores da Comunidade Maguari", encontra-se cadastrado no Comitê de Ética em Pesquisa - CEP da Universidade Federal do Amazonas - UFAM, através da PLATAFORMA BRASIL, sendo "APROVADO" em 24 de janeiro de 2014, com Parecer do Comitê de Ética/CAAE, número 26830514.9.0000.5020.

\section{RESUlTAdOS E DISCUSSÃo}

\section{Perfil dos entrevistados}

Foram conduzidas 146 entrevistas e, entre elas, $55 \%$ dos entrevistados foram do sexo feminino e $45 \%$, do sexo masculino, representando $51 \%$ dos entrevistados os com idade entre 26 e 40 anos, que trabalham e a maioria casada. Dentre os que trabalham, há os que ajudam na sobrevivência da família e não possuem renda alguma e há os que recebem. Estes recebem entre um e três salários mínimos. Destes, alguns são aposentados ou recebem o bolsa verde, com valor de $\mathrm{R} \$ 300$, de três em três meses, ou bolsa família. Outros trabalham na escola, como professores, vigia, secretário; no roçado; na agricultura com o cultivo de arroz, milho, mandioca para a produção de farinha; no ICMBio como fiscal, vigia; e também no artesanato.

A mandioca é a principal fonte de alimentação das comunidades na FLONA. A maioria das famílias possui casa de farinha própria (61\% das famílias); quando não, utilizam casas de farinha comunitárias. Da mandioca são retirados diversos subprodutos, como: farinha (diversos tipos), beiju, tapioca, tucupi (veneno contra formiga, conservas, sopas, tempero). Além da mandioca são muito consumidos o cará branco e cará roxo (CROMBERG e GRECO, 2008).

Segundo (MORAN, 1994), essa grande dependência da mandioca pode ser explicada pelas fortes características de adaptação dessa cultura ao solo e clima da região equatorial. A cultura de tubérculos apresenta uma grande produção por unidade de mão de obra e de terra. Além disso, são resistentes a pragas e podem ser deixados no solo tanto tempo quanto for necessário. Populações que habitam regiões costeiras ou ribeirinhas tornam-se mais facilmente sedentárias do que populações de caçadores seminômades.

É na agricultura que a prática do pousio se conserva nas comunidades. Primeiramente, é realizada a queimada daárea de plantio; em seguida, são retirados os tocos e faz-se um preparo manual do solo. Essa área é utilizada por um período de cinco a dez anos e depois é deixada "descansando". Durante o período de "descanso", o agricultor abre um novo roçado e a área anterior regenera-se formando capoeiras.

Entretanto, muitas vezes a queimada não era bem controlada, ocasionando danos irremediáveis à floresta circundante. Diante disso, o Instituto de Pesquisa Ambiental da Amazônia - IPAM vem implantando junto às comunidades o "Programa Bom Manejo do Fogo", instruindo os comunitários a realizar queimadas controladas. Além disso, outros projetos vêm contribuindo para a redução das queimadas com a 
introdução de práticas de agricultura ecológica, que buscam aproveitar o mesmo roçado por um maior tempo em substituição ao tradicional sistema de pousio (CROMBERG e GRECO, 2008).

Além da agricultura como subsistência dos moradores da comunidade, os grandes rios e grandes áreas costeiras oferecem recursos extraordinários que estimulam a pesca e horticultura, além do artesanato. A pesca é a principal fonte de obtenção de proteínas pelas comunidades da FLONA. As principais espécies consumidas são tucunaré, pirarucu, surubim e tambaqui (MORAN, 1994). Esse fato aponta a forte presença da relação dos ribeirinhos da FLONA com os rios e a atividade pesqueira.

Quanto à escolaridade, 63\% dos entrevistados possuem ensino fundamental completo ou incompleto, $23 \%$ possuem o ensino médio, $6 \%$ sabem ler e escrever, sem considerar algum tipo de formação diretamente na escola, $2 \%$ têm ensino superior e os outros $2 \%$ concluíram uma pós-graduação.

Das pessoas entrevistadas, 69\% são moradores que nasceram no local ou são filhos de pessoas que moram no local, ou seja, moradores que residiam no local, saíram por algum tempo, tinham seus filhos fora do local e depois retornavam. Muitos foram os motivos que levaram as pessoas a decidirem a morar ou retornar para a Comunidade Maguari.

Moradores que trabalham no local, como, por exemplo, na escola ou para o ICMBio, são aqueles que foram por causa de trabalho. Outros foram porque casaram com nativos da comunidade. Nas entrevistas, muitos disseram, também, que nasceram no local e mais tarde foram para a capital, mas depois de alguns anos preferiram retornar para ficar perto dos pais que permaneciam morando na Comunidade.

O tempo de residência dos moradores entrevistados na comunidade variou de 2 a 74 anos. De acordo com Diegues (1997), especialmente na Amazônia, é comum as populações se organizarem em comunidades rurais. Nessas comunidades, a apropriação e o uso dos espaços e recursos naturais caracterizam-se pela sua utilização comunal ou comunitária, por meio do extrativismo vegetal (cipós, fibras, ervas medicinais da floresta), do extrativismo animal (caça e pesca) e da pequena agricultura itinerante.

A grande maioria dos entrevistados gosta de morar na comunidade $(98 \%)$ e os outros $2 \%$ responderam que não. Provavelmente pela forte dependência dos recursos naturais ali existentes. Essa forma de organização é frequente entre as populações com forte dependência dos tais recursos para sua subsistência, demograficamente pouco densa e com vinculações mais ou menos limitadas com o mercado.

As comunidades residentes atualmente na Flona são resultados da miscigenação do povo indígena Tapajó com migrantes nordestinos, trazidos para a região para trabalhar nos seringais e, mesmo que em menor número, com povos africanos, trazidos como escravos pelos colonos portugueses.

Essas comunidades vêm crescendo demograficamente, devido ao grande número de nascimentos e ao regresso de jovens que saem em direção às cidades para estudar e voltam casados com pessoas de fora. Talvez por este fato, os comunitários vêm recebendo grande influência de padrões culturais urbanos, o que tem contribuído para a adoção de novas estratégias de adaptação. Essas novas estratégias supostamente estão relacionadas a diversos aspectos, como: o modelo de moradia ideal, as fontes de obtenção de proteínas na dieta das comunidades, o número de entradas na mata para coleta de produtos florestais não madeireiros, entre outros.

Embora as populações locais, sob regime de propriedade comum, ocupem um território comum (áreas devolutas ou áreas protegidas) e compartilhem o uso dos recursos ali existentes, isso não implica necessariamente em manejo comum de todos os recursos. Na prática existem poucas situações em que as atividades produtivas ocorrem sob manejo regulado por regras comuns. O que frequentemente ocorre é um continum de arranjos da apropriação e uso de recursos, que vai desde acesso aberto, uso comum até o uso individual, no qual as comunidades estão continuamente envolvidas em uma ou outra direção (BERKERS e FLOKE, 1994; RICHARDS, 1997).

Dos entrevistados, $43 \%$ confirmaram que as suas 
situações financeiras melhoraram após a criação da Flona do Tapajós. Muitos disseram que o turismo no local ajudou bastante a vida dos moradores, provavelmente devido à maior atenção dada ao local.

$\mathrm{O}$ ecoturismo funciona por meio de trilhas ecoturísticas e capacitação dos comunitários para atuarem como guias. O Projeto Saúde e Alegria - PSA tem benefícios com essas atividades, já que participa da receita líquida gerada. Além disso, durante as visitas são vendidos produtos e serviços (hospedagem e alimentação). Os produtos são gerados pelas oficinas de artesanatos e vendidos na comunidade e em uma loja anexada na sede do projeto em Santarém.

O fluxo de turistas aumenta no período do aparecimento das praias do Rio Tapajós. O ecoturismo é divulgado na mídia regional, nacional e internacional. As famílias oferecem a alimentação e a hospedagem a esses turistas, apesar de não disporem de uma estrutura adequada para tanto. A condução nas trilhas funciona em forma de rodízio.

\section{Gestão adotada na Floresta Nacional Tapajós}

A Flona Tapajós, com aproximadamente $545 \mathrm{mil}$ hectares, foi criada em 1974. O Ibama é o órgão gestor responsável juridicamente pelas ações de manejo na Flona do Tapajós. A Unidade conta com uma chefia local, que está subordinada administrativamente à Gerência Executiva II de Santarém e tecnicamente à Coordenação Geral de Florestas Nacionais CGFLO/Ibama. Os projetos que atuam na Flona, caso do ProManejo e Projeto ITTO, têm sistema administrativo e estrutura organizacional própria, mas atuam de forma integrada com a Gerência da Unidade. No caso do Projeto ITTO, a Chefia da Flona acumulou a função de gestor local durante a vigência do Projeto.

Da época da criação da Flona até meados da década de 90, a relação entre as populações residentes da Flona e a chefia do Ibama foi tensa e conflituosa. Somente em 1995, com a preparação do Promanejo, iniciou-se uma relação de negociação entre as comunidades e o Ibama sobre as questões de acesso e uso dos recursos naturais. Em 1996, em uma atividade de pré-investimento, o Imaflora coordenou a elaboração do Plano Diretor da Flona Tapajós, que a dividiu dez zonas de uso. Nesse mesmo ano, o PSA coordenou um plebiscito com 1.291 moradores. Desse total, a maioria (62\%) preferiu optar por ter as suas áreas fora da Flona. Esse fato revelou um grande descontentamento da comunidade com o modelo de gestão até então adotado pelo Ibama. Essa crise, por sua vez, criou a oportunidade para uma mudança na postura do Ibama com relação à gestão da Unidade. A partir daí, os fatos positivos se sucedem (VERÍSSIMO, 2005).

Nos anos seguintes, o Ibama e o Promanejo passaram a dialogar intensamente com as comunidades, as ONGs e o STR sobre a construção de uma agenda de trabalho e parceria. A entrada em vigor do Sistema Nacional das Unidades de Conservação - SNUC, no ano, deu umimpulso ainda maior à ideia de uma gestão participativa, pois esse novo marco regulatório reconhecia e valorizava o papel das populações nas Unidades de Uso Sustentável, como é o caso da Flona Tapajós. Em 2001, foi criado o Conselho Consultivo da Flona, com a participação de 21 membros, incluindo associações comunitárias, STR, ONGs, universidades, Embrapa, Emater e Ibama.

Os beneficiários diretos são aproximadamente 5.000 comunitários e pequenos produtores residentes nas 29 comunidades da Flona Tapajós e outros 5.000 moradores do município de Aveiro, situado dentro da Flona. A população existente nessa unidade de conservação é composta por: posseiros, colonos assentados do Instituto Nacional de Colonização e Reforma Agrária - Incra, mas, principalmente, por variados tipos de populações tradicionais (indígenas, pescadores, seringueiros, pequenos produtores, entre outros), que se distribuem em comunidades principalmente às margens dos rios e estradas. Estamos considerando os moradores da Flona do Tapajós "populações tradicionais", pelo fato de que estas são portadoras de experiências no uso e manejo da floresta e seus recursos preocupadas com a capacidade de recuperação das espécies animais e vegetais, que são indispensáveis para a garantia de sua subsistência.

De acordo com Diegues (1996), as "populações 
tradicionais" são aquelas cuja cultura reflete um "complexo de conhecimentos adquiridos pela tradição herdada dos mais velhos, de mitos e símbolos que levam a manutenção dos ecossistemas naturais". Essas populações possuem um conhecimento secular acerca dos ecossistemas onde constroem a sua existência material, vivem em quase simbiose com a natureza e seus ciclos, possuem sistema produtivo, em grande parte, vinculado à agricultura de subsistência e extrativismo com reduzida acumulação de capital, reservando considerável importância à unidade familiar ou comunal e às relações de parentesco ou compadrio para o exercício de suas atividades econômicas e sociais.

A organização dos comunitários e pequenos produtores no processo de negociação e implementação da gestão participativa é feita por meio de várias associações comunitárias e intercomunitárias (Associação Intercomunitária do Tapajós - AITA, Associação Intercomunitária Nova União do Tapajós - ASNUTA, Associação Intercomunitária de Mini e Pequenos Produtores Rurais da Margem Direita do Tapajós de Piquiatuba a Revolta - ASMIPRUT, Associação de Pequenos Produtores Rurais São Jorge, Santa Clara e Nossa Senhora de Nazaré APRUSANTA). Essas associações são o resultado de um longo processo de articulação dos moradores locais da Flona Tapajós para garantir representação política e obtenção de apoio técnico e financeiro para projetos de desenvolvimento comunitário. Mais recentemente, as associações comunitárias concordaram em formar uma federação (Federação das Organizações e Comunidades Tradicionais do Tapajós - FCFT) para ser a instância máxima de representação comunitária (VERÍSSIMO, 2005).

No entanto, o Projeto Saúde e Alegria enfatiza que ainda há muito a ser feito para atingir uma "gestão participativa" na Flona. O Conselho Consultivo deveria ter mais poderes e atuar na prática como Conselho Deliberativo. Tambémé importante atuar nas áreas de entorno da Flona onde há uma pressão crescente incursão de madeireiros para retirada ilegal de madeira, desmatamento nas bordas, etc.
Além disso, o processo atual de ocupação do entorno exige a superação da visão "paroquial", que enxerga apenas o que acontece dentro da Flona. É necessário colocar na agenda dos debates do Conselho estratégias para que a Unidade não fique apenas em posição defensiva frente à expansão desenfreada das monoculturas na região, mas que influencie o ordenamento da ocupação no entorno. Isso exige uma estratégia coordenada entre organizações da sociedade civil e órgão gestor e, portanto, novas posturas na construção de alianças (IBAMA, 2005).

As ONGs do Projeto Saúde e Alegria, Instituto de Pesquisas Ambientais da Amazônia - IPAM e Grupo de Defesa da Amazônia - GDA, pessoas jurídicas do terceiro setor, foram instituídas para uma missão mais ampla e não especificamente para atuar na Flona Tapajós. Essas instituições atuam diretamente no Conselho Consultivo da Flona, bem como na execução e apoio a vários projetos de conservação e desenvolvimento comunitários. Essas ONGs têm tido um papel importante no apoio ao fortalecimento das organizações comunitárias.

O Ibama, por meio da chefia da Flona e sua equipe técnica, tem mandato constitucional para administrar e conservar a Flona Tapajós. A chefia da Flona tem escritório no Ibama Santarém. O Promanejo possui uma equipe com atuação nas áreas de educação ambiental, ecoturismo, monitoramento ambiental e manejo florestal comunitário.

A Federação das Comunidades e Oranizações Sociais constitui a principal rede de atuação e representação dos comunitários. A criação da Federação é uma resposta à necessidade de unificar e ampliar a representação política dos moradores da Flona. Há um certo grau de heterogeneidade das associações que são membros da rede em função de sua localização: na margem do Tapajós há mais interesse em manejo florestal, e na margem da BR163 há mais pressão para a agricultura, além do grau de organização e existência ou não de projetos de desenvolvimento florestal com apoio do Promanejo (VERÍSSIMO, 2005).

Do ponto de vista da gestão administrativa, a pouca 
autonomia no gerenciamento financeiro por parte da gerência da Unidade, os poucos recursos liberados anualmente pelo POA e a impossibilidade de aplicar na Unidade os recursos que ela gera - caso da concessão para exploração de madeira no Projeto ITTO - são problemas estruturais, cuja solução foge da governabilidade da Unidade. Um outro aspecto a ser considerado é a redução abrupta da equipe da Flona em 2004, resultado da transferência de analistas que haviam sido contratados em novembro de 2002. Com a iminência de encerramento do ProManejo e a dissolução da equipe contratada que apoia o órgão gestor na execução das atividades, a execução do Plano de Manejo ficará completamente comprometida no caso de a equipe da Flona/IBAMA não ser reestruturada (IBAMA, 2005).

Dessa forma, a exemplo de outras Unidades, a agenda do Conselho Consultivo deve incorporar a discussão de alternativas de captação de recursos e gestão financeira que permitam maior autonomia e sustentabilidade das atividades e fazer gestão para que o Ibama reestruture a equipe de analistas da Flona do Tapajós.

\section{Percepção dos entrevistados}

Dentre os moradores entrevistados da Comunidade Maguari, $85 \%$ afirmam, do ponto de vista pessoal, que a gestão da Flona Tapajós é eficiente e 76\% acreditam que a população local está de acordo com a atual gestão. Eles confirmam, também que os moradores percebem tal eficácia da Flona na Comunidade Maguari. Quando questionados, os entrevistados, quanto ao grau de aprovação da eficácia da gestão na Flona do Tapajós, 51\% disseram ser bom.

Grande parte dos entrevistados (92\%) reconhece que há limites a respeito do uso dos recursos naturais dentro da Comunidade Maguari. É conhecido pelos moradores que tais limitações estão no roçado, na retirada de madeira, na caça, na criação de certos animais como bois ou porcos, na pesca e que não se pode tirar nada sem autorização dos responsáveis. A comunidade preserva aquilo que ainda existe de floresta, porque sabem que é isso que mais tarde vai trazer benefícios para as suas famílias.

Na Comunidade Maguari, a fabricação de bolsas e acessórios feitos de couro é a principal fonte de renda de algumas famílias e moradores afirmaram que, antes, trabalhavam fazendo imensos roçados, degradando muito a floresta. Hoje, com o artesanato e com a venda de biojoias, a utilização do couro ecológico e o ecoturismo não estão degradando o meio ambiente e também promovem o crescimento econômico na localidade.

O couro ecológico é produzido combase em tecido de algodão, onde são aplicadas oito camadas de látex da seringueira para fazer cada lado do couro que, submetido a um processo de secagem, se torna impermeável e resistente. O produto final é muito semelhante ao couro animal. Atualmente, a comunidade vende o couro ecológico para consumidores do Brasil e da Europa. Com o apoio recebido de entidades diferentes, como ProManejo/PPG7, Flona do Tapajós, Ibama/Usaid e Instituto Internacional de Educação no Brasil, a comunidade já conseguiu construir galpões e comprar novos equipamentos.

E, mesmo com tantas limitações, ainda houve aquelas pessoas que afirmaram não reconhecer proibições na Comunidade e aquelas que negaram existir tais proibições a respeito do uso dos recursos no local. Essa resposta concorda com respostas de alguns moradores que disseram que algumas pessoas usam os recursos naturais locais de qualquer forma. Os moradores que reconhecem tais limitações afirmaram que as proibições são necessárias para preservar o que tem na floresta para a sua própria subsistência e sobrevivência das espécies que ali vivem, tanto animais como vegetais, que podem ser extintas do local com o uso exploratório da natureza.

Atualmente, o Estado do Pará tem centralizado as decisões sobre o uso dos recursos naturais, transformando as áreas comunais em áreas públicas. A despeito da crescente consciência do papel vital da propriedade comum para os sistemas locais de manejo e para a conservação dos recursos às comunidades, que dependem do seu uso para a manutenção de seus modos de vida. Muitos tomadores de decisão duvidam 
da capacidade das comunidades locais de manejarem seus próprios recursos, acreditando que somente o controle estatal sobre as áreas utilizadas em comum podem prevenir a degradação dos recursos (OSTROM, 2000).

As alternativas, que variam desde o controle total pelas comunidades até o manejo cooperativo entre Estado e comunidades, são relativamente recentes e raros. Políticas para a transferência das responsabilidades e direitos sobre manejo dos recursos naturais do Estado para instituições não governamentais, particularmente para as populações locais, tornaramse mais comuns nos últimos 20 anos (MCCULLOCH e MEINZEN-DICK, 2001).

Um dos objetivos da Flona do Tapajós, descrito no Decreto n. ${ }^{\circ} 1.298$, de 27/10/1994, é promover o manejo dos recursos naturais, comênfase na produção de madeira e outros produtos vegetais e, também, garantir a proteção dos recursos hídricos, das belezas cênicas e dos sítios históricos e arqueológicos; e fomentar o desenvolvimento de pesquisa científica e básica aplicada, da educação ambiental e das atividades de recreação, lazer e turismo.

Em um relatório de auditoria operacional, realizado pelo Tribunal de Contas da União, em 2008, concluiuse que a unidade de conservação se mantém razoavelmente bem protegida de ações predatórias, embora haja registro de extração ilegal de madeira, principalmente nas regiões localizadas próximas ao seu limite sul, e persista forte pressão antrópica no seu entorno. Observou-se que as atividades desenvolvidas pelo ProManejo têm desempenhado papel indutor para a conscientização da importância da exploração sustentável dos recursos da floresta. Por outro lado, detectaram-se indícios de irregularidade no processo de concessão de parte da unidade para fins de manejo florestal sustentável.

A sustentabilidade econômica existe em Maguari para $63 \%$ dos entrevistados. Verificou-se que a
Comunidade possui características muito comuns quanto às atividades econômicas, e isso obviamente acontece em função das características da floresta, e dos recursos naturais disponíveis para exploração comercial.

Conforme pode ser constatado na Lei do Sistema Nacional das Unidades de Conservação - SNUC, de 2000, a qual, apesar de representar uma conquista para as populações moradoras em unidades de conservação por permitir sua permanência nos seus limites, impõe a elas uma série de regras de conduta referentes ao uso dos recursos naturais e o dever de se comportarem para continuar morando lá.

Segundo o Plano de Manejo, a insatisfação destes em relação ao modelo de gestão até então adotado pôde ser observado em 1996, quando o Projeto Saúde e Alegria organizou um plebiscito para levantar quais moradores tinham o desejo de ter suas áreas nos limites da unidade ou excluídas destes, tendo como resultado $62 \%$ dos consultados optando por ter suas áreas excluídas da unidade (IBAMA, 2005).

A questão fundiária foi definitivamente resolvida. A solução definida para a questão foi a assinatura de um termo de ajustamento de conduta entre o Ibama e o Ministério Público Federal e a transferência das terras da SPU para o Ibama. Além disso, cerca de 437.000 hectares da unidade pertencem ao Incra, 130 mil à Secretaria de Patrimônio da União e 20.000 ao Iterpa, a serem transferido para o Ibama, o que dificulta a assinatura do Contrato de Concessão Real de Uso aos moradores da unidade e a regularização da questão fundiária.

Todos os moradores entrevistados afirmaram que a Comunidade necessita de um posto de saúde e $69 \%$ pedem melhores condições para a estrada que utilizam para sair de Maguari, pois, segundo eles, a estrada se encontra em condições precárias para o uso. O Gráfico 1 apresenta quais são as maiores necessidades da Comunidade. 


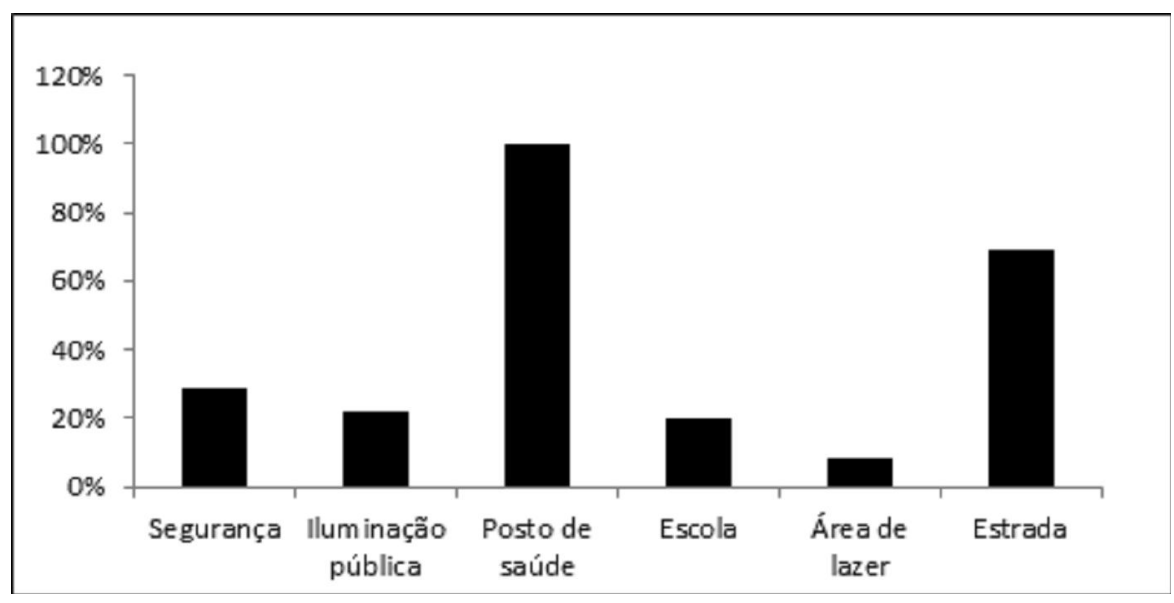

Gráfico 1 - Representação gráfica das necessidades dos moradores de Maguari.

Fonte: Dados de pesquisa.

A saúde é a principal reivindicação dos moradores, embora o sistema público venha se aperfeiçoando gradativamente. É difícil o acesso à rede assistencial e a maioria das comunidades não possui posto de saúde. As condições de higiene são precárias e as águas fluviais estão contaminadas por dejetos lançados nos rios. Doenças simples tornam-se graves devido à falta de atendimento efetivo e adequado. Embora a mortalidade infantil esteja diminuindo consideravelmente, doenças como diarreia, infecções respiratórias agudas e outras doenças imunizáveis, que poderiam ser prevenidas, ainda ocorrem com frequência. Adesnutrição infantil está associada à época das cheias, quando o peixe se torna escasso. Anemias, parasitoses, doenças de pele e problemas orais estão presentes em praticamente todas as crianças. A maioria das gestantes não realiza pré-natal, e a maior parte dos partos é feita em casa, elevando os índices de mortalidade materna e fetal. Embora a malária esteja controlada na região, é alta a incidência de outras endemias, como hanseníase, tuberculose e leishmaniose, além de zoonoses e outras doenças infecciosas (BARROSO, 2003).

Depois da criação da Flona, a qualidade de vida dos moradores da Comunidade Maguari pode ser melhor, segundo $67 \%$ dos entrevistados; $18 \%$ afirmam que há deficiências nos projetos implantados e que não atende às necessidades dos moradores. Com a gestão implantada na Flona, a Comunidade melhorou um pouco, de acordo com $40 \%$ dos moradores entrevistados.

A lei do SNUC define a Floresta Nacional como uma área com cobertura florestal de espécies predominantemente nativas e tem por objetivo básico o uso múltiplo sustentável dos recursos florestais e a pesquisa científica, com ênfase em métodos para exploração sustentável de florestas nativas. Portanto, as florestas nacionais são terras públicas federais destinadas à produção continuada de bens e serviços de origem florestal. Nas Florestas Nacionais é admitida a permanência de populações tradicionais que a habitam quando de sua criação, em conformidade com o disposto em regulamento e no Plano de Manejo da Unidade.

\section{Sugestões para a melhoria da gestão adotada na Flona}

Dentre os entrevistados, consideram-se que cursos, treinamentos e reuniões são atividades que faltam para a Comunidade Maguari. Os moradores sentem a necessidade de cursos de qualificação profissional, de estarem mais informados com o que acontece em relação à Flona e, principalmente, o que envolve a Comunidade Maguari. A maioria sugeriu que a gestão 
presente busque mais parcerias com instituiçoes de ensino e que fosse criado um modelo melhor de gestão com mais sustentabilidade.

A Gerência da Flona do Tapajós dispõe de um grupo bem estruturado no que diz respeito à fiscalização da área. Utilizam recursos tecnológicos adequados e tem criado metodologias de trabalho eficazes, que conciliam imagens de satélite com pontos de levantamento em sobrevoos de avião com vistas ao planejamento das ações de campo tanto dentro da unidade quanto no seu entorno. Embora efetue ações de fiscalização com alguma frequência, a extensão da área a controlar e o número reduzido de fiscais são fatores que pesam contra uma maior efetividade das ações.

A Coordenação de Monitoramento, Controle e Fiscalização da Floma acrescenta que, em virtude do alto valor comercial e baixa punição legal aos infratores de extração ilegal de madeira, esse éumnegócio lucrativo por qual vale à pena o risco, o que torna a tarefa de fiscalização ainda mais complexa. Na Floresta Nacional do Tapajós, há boas práticas sendo implementadas, cujos resultados positivos recomendam sua adoção para outras unidades de conservação de igual natureza. As inúmeras pesquisas científicas realizadas em seu interior mostram que, nesse item, a unidade atende a um dos requisitos para a qual foi criada.

O Conselho Consultivo tem-se mostrado um instrumento de participação coletiva importante no planejamento e na avaliação de medidas voltadas ao bom gerenciamento da unidade. Ações junto às populações ribeirinhas, especialmente as do ProManejo, mostram que há como conciliar a exploração dos recursos florestais sem que isso signifique necessariamente exaustão da floresta ou destruição de seus ecossistemas, ao tempo em que se proporciona fonte de renda adequada às famílias beneficiadas. Ou seja, é possível às comunidades tradicionais a utilização dos recursos naturais da Flona Tapajós de maneira ambientalmente sustentável.

Se as populações tradicionais são beneficiadas com os produtos provenientes da floresta, as riquezas biológicas encontradas na Amazônia são preservadas por essas comunidades que atuam como guardiãs da natureza, reduzindo gradativamente a exploração dos recursos naturais pelos grileiros, sojeiros, pecuaristas e demais criminosos ambientais interessados em destruir a biossociodiversidade da maior floresta tropical do planeta.

\section{Conclusões}

As intervenções realizadas na Flona do Tapajós ocorrem por meio de inúmeros projetos e programas direcionados à mudança de comportamento dos moradores de Maguari quanto à preservação e conservação do meio ambiente, mas o modelo de gestão adotada pela Floresta Nacional do Tapajós ainda deixa a desejar, segundo a percepção dos moradores da Comunidade, mesmo com um plano de manejo existente. A análise da percepção dos moradores poderá dar subsídios a novas decisões para uma gestão ambiental e social mais eficaz e satisfatório para a população local.

$\mathrm{Na}$ Comunidade Maguari, reclamações como ausência de um posto de saúde foram muito frequentes, além da falta de mais reuniões entre eles e o ICMBio para que melhorem as condições de vida dos moradores. Os moradores sentem a necessidade de cursos e treinamentos para informá-los melhor do que pode ser feito e como e onde possam buscar alternativas para a população, já que eles não podem tirar madeira, além de outras limitações, como no roçado e na plantação. O couro ecológico é direcionado só para 19 famílias, e estas passam por alguns problemas entre eles e anseiam em cursos para uma melhora na produção desse couro. Quem recebe mais de um salário mínimo é apenas quem trabalha na escola e para o ICMBio ou é aposentado, porque a maioria recebe menos que um salário mínimo, que consegue com a venda da farinha e da pesca.

Apesar disso, conclui-se que os entrevistados consideram a gestão adotada pela Flona de Tapajós boa. Os moradores desejam a implementação de um posto de saúde e de melhorias na estrada, assim como qualificação profissional para a região local.Aqualidade de vida na Comunidade pode ser melhorada a partir 
da união de mais parcerias institucionais que visem à sustentabilidade dos recursos.

Os moradores reconhecem que o localé uma área de proibições e os recursos naturais devem ser utilizados de forma limitada, para que se preserve o que se tem e para a subsistência da população local, pois para que possa ocorrer o desenvolvimento sustentável na região, fazem-se necessários planejamento e reconhecimento da finitude dos recursos naturais. Por solicitar a integração de soluções nos campos econômico, social, político e ambiental, o desenvolvimento sustentável é um grande desafio para a humanidade. São necessárias mudanças no estilo de desenvolvimento da sociedade, economia no consumo de matérias-primas e energia e equidade na distribuição social dos resultados.

\section{REFERÊNCIAS}

BARROSO, M. M. Projeto Saúde e Alegria: um ensaio crítico. Cadernos de Gestão pública e cidadania. FVG, Rio de Janeiro, 2003.

\section{BERKES, F.; FOLKE, C. Linking social and} ecological systems for resilience and sustainability. Stockholm: Beijer International Institute of Ecological Economics, 1994. 16p. (Beijer Discussion Paper Series, 52).

CROMBERG, M.; GRECO, T. M. Estratégias de Adaptação das comunidades na Floresta Nacional doTapajós. Escola Superior de Agricultura Luiz de Queiroz, , 2008. 19p.

DIEGUES, A. C. Repensando e recriando as formas de apropriação comum dos espaços e recursos naturais. In: VIEIRA, P. F.; WEBWER, J (Org). Gestão de recursos naturais e desenvolvimento: novos desafios para a pesquisa ambiental. São Paulo: Cortez, 1997. p.407-432.
IBAMA. Plano de Manejo da Floresta Nacional do Tapajós. 2005. 200p.

MCCULLOCH, A. K.; MEIZEN-DICK, R. Collective action, property rights, and devolution of natural resource management: exchange of knowledge and implications for policy. Washington: IFPRI, 2001. 63p. (CAPRi Working Paper, 11).

MMA - MINISTÉRIO DO MEIO AMBIENTE. Relatório Final: Contribuição das Unidades de Conservação Brasileiras para a Economia Nacional. Rio de Janeiro, 2011.

MORAN, F. Adaptabilidade Humana: Uma Introdução à Antropologia Ecológica. São Paulo: Editora Universidade de São Paulo, 1994. v.10, $445 p$.

OSTROM, E. El governo de los bienes comunes: la evolución de las instituciones de acción coletiva. Cidade do México: Universidade Nacional Autônoma de México, 2000. 395p.

\section{PEREIRA, L. A. da C. Mineração de granito} para britagem: uma contribuição ao desenvolvimento regional. Dissertação de mestrado em desenvolvimento regional e meio ambiente. Rondônia: UNIR, 2004.

RICHARDS, M. Tragedy of the commons commuity-based forest management in Latin America? London: ODI, 1997. 9p. (Natural Resource Perspectives, 22).

VERÍSSIMO, A. Influência do PROMANEJO sobre políticas públicas de manejo florestal sustentável na Amazônia. Brasília: Ministério do Meio Ambiente (Série Estudos nº 03), 2005.

RECEBIDO EM 30/2/2014

ACEITO EM 15/10/2014 